\title{
Development of Short-Form of the Speech Handicap Index and Its Application to Tongue Cancer Patients
}

\author{
Sun-A Wee ${ }^{a}$, Eun-Chang Choi ${ }^{\mathrm{b}}$, Sung-Rae Cho ${ }^{\mathrm{c}}$, Seong Hee Choi ${ }^{\mathrm{d}}$, HyangHee Kim ${ }^{\mathrm{a}, \mathrm{b}}$ \\ ${ }^{a}$ Graduate Program in Speech and Language Pathology, Yonsei University, Seoul, Korea \\ ${ }^{b}$ Department of Otorhinolaryngology, Yonsei University College of Medicine, Seoul, Korea \\ 'Department and Research Institute of Rehabilitation Medicine, Yonsei University College of Medicine, Seoul, Korea \\ ${ }^{d}$ Department of Audiology and Speech-Language Pathology, Catholic University of Daegu, Gyeongsan, Korea
}

Correspondence: HyangHee Kim, $\mathrm{PhD}$ Graduate Program in Speech and Language Pathology, Yonsei University, 50-1 Yonsei-ro, Seodaemun-gu, Seoul 03722, Korea

Tel: $+82-2-2228-3902$

Fax: +82-2-2227-7984

E-mail: h.kim@yonsei.ac.kr

Received: January 15, 2018 Revised: February 5, 2018

Accepted: February 5, 2018

\begin{abstract}
Objectives: The Speech Handicap Index (SHI) is one of the self-report assessments and questionnaires to assess speech problem of patients with oral or oropharyngeal cancer. Although $\mathrm{SHI}$ is a reliable and valid questionnaire for assessing the speech problem, it is a time-consuming test with 30 items. Therefore, the current study developed a short-form of the SHI and evaluated its reliability and validity in tongue cancer patients. Methods: The study was comprised of two steps. For Step I, the SHI with 30 items was administered to 56 participants with tongue cancer and we performed Rasch analysis to select items. Then, two experts agreed upon 15 items which would best manifest degrees of quality of life in patients with various speech disorders (not limited to cancer patients). The resulting SHI-15 was comprised of 8 items of the speech function subdomain and 7 items of the psychosocial subdomain. In Step II of the study, both the SHI-30 (30-item full version) and SHI-15 were administered to 35 patients with tongue cancer and 35 healthy individuals to evaluate the reliability and validity of the SHI-15. Results: The SHI- 15 had high internal consistency and test-retest reliability. With the high correlation between the $\mathrm{SHI}-30$ and the SHI15 , SHI-15 demonstrated itself to be a viable alternative tool to the SHI-30. In addition, the SHI-15 was proven to have high sensitivity and specificity in differentiating between the patient and healthy groups. Conclusion: This study is significant in that it shows the timeefficient SHI-15 can be a useful tool for evaluating a patient's self-perception of his or her speech, psychosocial function, and degree of speech problems. The SHI-15 can be utilized in a routine evaluation protocol in a clinical setting to maximize patients' quality of life related to speech problems.
\end{abstract}

Keywords: Speech Handicap Index, Tongue cancer, Quality of life, Rasch analysis
말장애는 조음 및 발성 기관의 구조상의 문제와 기능상의 문제 등 다양한 원인에 의해 발생한다. 구조상의 문제는 말 산출에 필요 한 호흡, 발성, 공명, 조음기관 구조의 부재 혹은 마비로 인한 것을 일컬으며 의사소통에 관여하는 신체구조는 두경부에 밀집되어 있 기 때문에 두경부암으로 인한 절제 및 치료는 의사소통에 지대한 영향을 미친다. 세계적으로 두경부암은 7번째로 흔한 암이며, 매년 300,000 명이 두경부암으로 사망하는 등 사망 원인 암들 중 9번째 로 빈번하다(Ferlay et al., 2015). 두경부 구조 중 혀는 조음에 주로 관여하는 구조로 혀의 절제는 말 문제에 직접적인 영향을 주기 때
문에 두경부암 중 설암이 다른 암들에 비해 삶의 질에 미치는 영향 이 크다. 설암 환자의 치료를 위해 최우선적으로 진행되는 것은 암 이 생긴 구강 혹은 얼굴 중앙부분의 수술적 제거이다(Funk et al., 2002). 이는 기능적 제한을 주기 때문에 환자들은 종종 심리적으로 나 생리적으로 어려움을 겪는다(Fingeret et al., 2013). Karnell, Funk 와 Hoffman (2000)에 따르면, 삶의 질에 영향을 미치는 다양한 요 소들 중에서 말 능력과 삼킴 능력은 설암을 포함한 두경부암 환자 삶의 질의 결정적 요소이다.

말장애의 말 평가는 다양한 측면에서 이뤄지는데 일반적으로 시 
각적, 음향학적, 공기역학적, 청지각적 평가와 조음기관의 검사 모 두가 포함된다(Boone, McFarlane, Von Berg, \& Zraick, 2013). 그러 나 이러한 음성측정 기계나 시각적인 비디오 인식 측정만으로는 환 자와 관련된 모든 문제를 파악하는 데 제한점을 갖기 때문에 환자 가 자신의 말 문제를 어떻게 생각하고 있는지에 대한 정보를 제공 하는 자기보고 평가는 말 문제 평가에 있어서 필수적이다(Rinkel, Leeuw, van Reij, Aaronson, \& Leemans, 2008).

2001년 세계보건기구(World Health Organization)에서는 International Classification of Functioning, Disability and Health (ICF) 에 따라 장애를 신체구조와 기능의 변화, 환자의 삶에 참여하는 능 력과 환경적 영향, 개인적인 요소를 포함하여 생물심리사회 체계의 이해까지 확대하였다(World Health Organization, 2001). 이처럼 장애에 대한 정의가 사회참여까지 포함됨에 따라 평가에 포함되는 삶의 질 관련 자기보고 평가는 필수적이 되었다.

그러나 대체적으로 삶의 질을 평가하는 설문지에는 말 문제를 평가하는 문항 수가 극히 제한적이다. 두경부암 환자들에게 삶의 질 평가도구로서 가장 많이 사용되는 The University of Washington Quality of Life Head and Neck Questionnaire of Life (UWQOL-R)는 말 문제를 평가하는 문항은 1개뿐이다(Rogers et al., 2002). 그 외에 Quality of Life Questionnaire-Head \& Neck module (QLQ-H\&N35)은 총 35문항 중 말 문제 평가문항이 3개이며 (Terrell et al., 1997), Functional Assessment of Cancer TherapyHead \& Neck (FACT-H\&N)도 총 20문항 중 말 문제 평가문항은 2 개뿐이다(Funk et al., 2003).

문항 수가 제한적일 뿐만 아니라, 구강이나 구인두암 환자의 특 별한 말 문제를 평가하기 위한 특화된 설문지가 없기 때문에 2008 년 네덜란드의 Rinkel 등에 의해 30문항으로 구성된 말장애지수 (Speech Handicap Index, SHI)가 개발되었다. 2016년 한국어로 번 안되어 두경부암 환자를 대상으로 한 연구에서는 높은 타당도와 신뢰도를 가지는 도구임이 판명되었다(Park et al., 2016).

SHI가 말 문제를 평가하기에 적합하게 개발되었음에도 30 개 문 항을 임상에서 실제로 사용하기에는 문항 수가 많아 시간적인 제 약을 받는다(Rosen, Lee, Osborne, Zullo, \& Murry, 2004). 이에 Sadura 등(1992)은 "자가 완성 설문지는 이해하기 쉬워야 하며 10 분 이내로 완성되도록 구성되어야 한다”고 제안하였다. 말 평가가 다 양한 객관적 평가와 함께 이루어지는 것을 고려할 때 30 문항으로 구성된 말장애지수는 평가의 시간적 효율성을 떨어뜨릴 수 있다. 이에, 본 연구에서는 SHI의 축약판을 개발하고 축약판이 타당한지 여부를 두 단계(연구단계 I, II)의 연구를 통해 살펴보았다.

\section{연구방법}

\section{연구단계 I: SHI 문항 축소}

연구대상

연구대상은 만 18 세 이상의 설암 환자 56명(남 36명, 여 20명)으로, 연세대학교 생명윤리위원회(IRB No. 7001988-201709-HR-264-02) 에서 승인을 받은 후 2017년 9월 8일부터 11월 13일 사이에 신촌세 브란스병원 이비인후과에 내원한 환자들을 대상으로 하였다. 종양 의 크기나 위치, 퍼진 범위는 구분 없이 모집하였으며 (1) 사례면담을 통해 말에 영향을 미치는 신경근 질환이 있는 자와, (2) K-MMSE 검사를 통해 인지적 문제가 있는 자(Kang, Jeong, Moon, Lee, \& Lee, 2016)는 제외하였다. 피험자 정보는 다음과 같다(Table 1).

\section{연구방법}

모든 검사는 조용한 환경에서 대상자와 일대일로 진행하였으며 사례면담을 통해 대상자의 생년월일, 성별, 교육년수, 진단명, 발병 일, 종양림프절전이(tumor, node, and metastasis, TNM), 복용하 는 약에 대한 정보를 수집한 후 한국판 $\mathrm{SHI}$ 를 실시하였다.

\section{자료분석}

자료는 WINSTEPS version 3.72.3 소프트웨어를 이용하여 라쉬 분석을 하였다. 라쉬모형에서 모형의 적합성은 적합도 지수에 의해

Table 1. Demographic information of Step I subjects ( $N=56)$

\begin{tabular}{lc}
\hline & Value \\
\hline Gender & 36 \\
Male & 20 \\
Female & $53.39 \pm 13.86(27-78)$ \\
Age (yr) & $14.36 \pm 2.78(9-18)$ \\
Education (yr) & $27.55 \pm 1.99(24-30)$ \\
K-MMSE & $3.43 \pm 3.15(1-14)$ \\
POT (yr) & \\
T classification & $28(50)$ \\
T1 & $19(33)$ \\
T2 & $4(7)$ \\
T3 & $5(8)$ \\
T4 & \\
N classification & $39(69)$ \\
N0 & $6(10)$ \\
N1 & $11(19)$ \\
N2
\end{tabular}

Values are presented as mean $\pm \mathrm{SD}$ (range) or number of subjects (\%). K-MMSE = Korean version of the Mini-Mental State Examination; POT = post-onset time; $\mathrm{T}=$ tumor; $\mathrm{N}=$ node. 
결정되는데 선행연구(Bond \& Fox, 2007; Kim, Shin, Kim, \& Kim, 2012)를 바탕으로 내적합지수와 외적합지수의 평균자승잔차의 값 이 .6보다 작거나 1.3 보다 크면 적합도 지수상 부적절한 문항으로 판단하였다. 또한, 축소판을 설암 환자뿐만 아니라 다양한 말장애 군에게 적용하기 위해 관련 분야 전문가 2 명의 자문을 받아 최종본 을 확정하였다.

\section{연구단계 II: SHI 축소판의 신뢰도와 타당도, 민감도 및 특이도 검증}

\section{연구대상}

연구대상은 연구단계 I과는 별도로 수집된 만 18 세 이상의 설암 환자 35 명과 정상군 35 명으로서, 환자군은 연세대학교 생명윤리위 원회(IRB No.7001988-201709-HR-264-02)에서 승인을 받은 후 2017년 11월 16일부터 12월 11일 사이에 신촌세브란스병원 이비인 후과에 내원한 환자들을 대상으로 하였다. 종양의 크기나 위치, 퍼 진 범위는 구분 없이 모집하였으며 (1) 사례면담을 통해 말에 영향 을 미치는 신경근 질환이 있는 자와, (2) K-MMSE 검사를 통해 인 지적 문제가 있는 자로 설정하여 대상자에서 제외하였다(Kang et al., 2016). 피험자 정보는 다음과 같다(Table 2).

\section{연구방법}

연구단계 II 역시 연구단계 I과 동일한 연구방법을 적용하였으

Table 2. Demographic information of Step II subjects $(\mathrm{N}=70)$

\begin{tabular}{lcc}
\hline & $\begin{array}{c}\text { Patient group } \\
(\mathrm{N}=35)\end{array}$ & $\begin{array}{c}\text { Normal control group } \\
(\mathrm{N}=35)\end{array}$ \\
\hline Gender & & 18 \\
Male & 24 & 17 \\
Female & 11 & $60.40 \pm 6.39(47-80)$ \\
Age (yr) & $55.97 \pm 12.46(34-88)$ & $14.97 \pm 2.13(12-18)$ \\
Education (yr) & $13.63 \pm 2.48(9-18)$ & - \\
K-MMSE & $26.74 \pm 1.50(24-30)$ & $27.49 \pm .95(25-29)$ \\
P0T (yr) & $3.82 \pm 2.89(1-13)$ & - \\
T classification & & - \\
T1 & $20(57)$ & - \\
T2 & $11(31)$ & - \\
T3 & $1(2)$ & - \\
T4 & $3(8)$ & - \\
N classification & & - \\
N0 & $26(74)$ & - \\
N1 & $4(11)$ & $5(14)$ \\
N2 &
\end{tabular}

Values are presented as mean \pm SD (range) or number of subjects (\%). K-MMSE = Korean version of the Mini-Mental State Examination; POT = post-onset time; $\mathrm{T}=$ tumor; $\mathrm{N}=$ node.
며, 추가적으로 SHI-15를 실시하였다.

\section{자료분석}

자료는 SPSS Window version 24.0을 이용하여 분석하였다. 신 뢰도 검증을 위한 문항내적일관성 신뢰도를 검정하기 위해 Cronbach's alpha를 실시하였고 검사-재검사 신뢰도를 확인하기 위해 전체 대상자의 $10 \%$ (7명)를 대상으로 1 차 검사일로부터 1 주일 후 에 재검사하여 피어슨 상관분석을 실시하였다. 타당도 검증을 위 해 SHI와 SHI-15의 점수에 대해 피어슨 상관분석을 하였으며, 문항 변별도 검증을 위해 피어슨 상관분석을 실시하였다. 두 집단을 변 별할 수 있는 도구인지를 확인하기 위해 민감도 및 특이도 검증을 실시하였다.

Table 3. Results of Rasch analysis on the Speech Handicap Index items

\begin{tabular}{|c|c|c|c|c|}
\hline \multirow{2}{*}{ Item } & \multicolumn{2}{|c|}{ Infit } & \multicolumn{2}{|c|}{ Outfit } \\
\hline & Mean square & Z-score & Mean square & Z-score \\
\hline 1 & 1.13 & .7 & 1.33 & 1.1 \\
\hline 2 & 1.82 & 2.5 & 1.73 & 1.3 \\
\hline 3 & 1.33 & 1.5 & 1.38 & 1.3 \\
\hline 4 & .76 & -1.1 & .67 & -1.2 \\
\hline 5 & 1.21 & 1.0 & 1.07 & .4 \\
\hline 6 & 2.17 & 3.9 & 2.52 & 3.1 \\
\hline 7 & 1.01 & .1 & .70 & -.7 \\
\hline 8 & .49 & -2.8 & .44 & -2.4 \\
\hline 9 & .85 & -.3 & .85 & -.4 \\
\hline 10 & .44 & -3.2 & .46 & -2.3 \\
\hline 11 & .54 & -2.4 & .62 & -1.2 \\
\hline 12 & .46 & -2.9 & .47 & -2.0 \\
\hline 13 & .54 & -2.4 & .58 & -1.6 \\
\hline 14 & .63 & -1.8 & 1.26 & .9 \\
\hline 15 & 1.10 & .5 & 1.20 & .8 \\
\hline 16 & .83 & -.7 & .88 & -.4 \\
\hline 17 & 3.69 & 7.5 & 2.62 & 4.2 \\
\hline 18 & .68 & -1.6 & .66 & -1.3 \\
\hline 19 & .93 & -.2 & .77 & -.6 \\
\hline 20 & .74 & -.6 & 1.07 & .3 \\
\hline 21 & 1.30 & 1.3 & 1.19 & .7 \\
\hline 22 & 2.07 & 3.7 & 1.59 & 1.6 \\
\hline 23 & 1.04 & .2 & 1.53 & 1.6 \\
\hline 24 & .64 & -1.8 & .55 & -1.6 \\
\hline 25 & 1.07 & .4 & .86 & -.4 \\
\hline 26 & .76 & -1.1 & .59 & -1.2 \\
\hline 27 & .97 & .0 & .87 & -.4 \\
\hline 28 & .56 & -2.3 & .59 & -1.7 \\
\hline 29 & .87 & -.5 & .70 & -.9 \\
\hline 30 & .90 & -.4 & .69 & -.9 \\
\hline
\end{tabular}

Bold text indicate .6 and over, 1.3 and under. 


\section{연구결과}

\section{연구단계 I: $\mathrm{SHI}$ 문항 축소}

라쉬분석을 통해 적합도 지수상 적합한 문항으로 선정된 문항 은 $4,5,7,9,14,15,16,18,19,20,21,25,27,29,30$ 번이었고(Table 3), 전문가의 자문을 받았을 때 그 중 25 번과 30 번은 제외되었고 1 번과 28 번이 추가되었다. 최종적으로 말 기능 8 문항, 심리사회적 기능 7 문항으로 구성된 총 15 문항의 축소판이 개발되었다(Table 4).

\section{연구단계 II: SHI-15의 신뢰도와 타당도, 민감도 및 타당도 검증} 신뢰도 검증

문항내적일관성을 검증하기 위해 Cronbach's alpha를 실시한 결 과, 전체문항 $(r=.976)$, 말 기능 문항 $(r=.950)$, 심리사회적 기능 문항 $(r=.961)$ 모두에서 높은 내적일관성이 보였다 $(p<.05)$.

재검사 신뢰도는 전체점수 $(r=.989)$, 말 기능 점수 $(r=.915)$, 심리 사회적 기능 점수 $(r=.909)$ 모두에서 높은 일치율을 보였다 $(p<.01)$
(Table 5).

\section{타당도 검증}

SHI와 SHI-15의 상관성

$\mathrm{SHI}$ 점수와 SHI-15 점수 간에 상관관계는 총점 $(r=.993)$, 말 기능 점수 $(r=.982)$, 심리사회적 기능 점수 $(r=.984)$ 로서 모두에서 높은 상관성을 보였다 $(p<.01)$ (Table 6).

\section{문항타당도}

문항타당도를 통한 문항변별도 검증에 있어서 총점과의 모든 문 항 $(r=.769-.937)$ 간에는 통계적으로 높은 수치를 보였다 $(p<.01)$ (Table 7).

\section{민감도 및 특이도}

SHI-15를 환자군과 정상군에게 실시한 결과를 바탕으로 receiver operating characteristic (ROC) curve 분석을 통해 민감도 및 타

Table 4. Short-form of the Speech Handicap Index (SHI-15)

\begin{tabular}{ll}
\hline Domain & \multicolumn{1}{c}{ Item } \\
\hline Speech & 1. My speech makes it difficult for people to understand me. (사람들은 내 말을 이해하기 어려워한다) \\
5. People ask me why I'm hard to understand. (사람들은 왜 내 말이 이해하기 어려운지를 내게 물어본다) & \\
9. My articulation is unclear. (나는 발음이 부정확하다) \\
15. I feel as though I have to strain to speak. (나는 말할 때 힘을 줘서 말해야 할 것 같다) \\
18. The intelligibility is unpredictable. (말 정확도(말을 정확하게 하는 정도)를 예측할 수 없다) \\
20. I use a great deal of effort to speak. (나는 말을 정확하게 하기 위해 노력을 한다) \\
21. My speech is worse in the evening. (저녁이 되면 말소리가 더 나빠진다) \\
28. I have difficulty continuing a conversation because of my speech. (나는 말 문제 때문에 대화를 계속(지속)하기 어렵다) \\
4. My speech makes me feel incompetent. (나는 말 때문에 무능력하게 느껴진다) \\
7. I avoid using the phone. (나는 전화사용을 피한다) \\
14. I speak with friends and neighbors or relatives less often because of my speech. (나는 말의 문제로 인해 친구, 이웃 혹은 친척들과 말을 덜하게 된다) \\
16. I find other people don't understand my speaking problem. (다른 사람들은 나의 말 문제를 이해하지 못하는 것 같다) \\
19. I feel left out of conversations because of my speech. (나는 말 문제 때문에 대화에서 소외감을 느낀다) ${ }^{a}$ \\
27. My speech makes me feel handicapped. (나는 말 문제 때문에 장애가 있다고 느껴진다) \\
29. I feel embarrassed when people ask me to repeat something. (나는 사람들이 다시 말해달라고 하면 당혹스럽다)
\end{tabular}

aPark et al. (2016)에 수록된 한국어 번안본 SHI문항들 중 수정된 4문항들을 지칭함(Appendix 1, Appendix 2).

Table 5. Reliability analysis for the SHI-15

\begin{tabular}{lccc}
\hline SHI domain & $\begin{array}{c}\text { Numbers of } \\
\text { items }\end{array}$ & $\begin{array}{c}\text { Internal consistency } \\
\text { (Cronbach's } \alpha \text { ) }\end{array}$ & $\begin{array}{c}\text { Test-retest reliability } \\
\text { (Pearson's } \eta \text { ) }\end{array}$ \\
\hline Total & 15 & $.976^{*}$ & $.989^{* *}$ \\
Speech & 8 & $.950^{*}$ & $.915^{* *}$ \\
Psychosocial & 7 & $.961^{*}$ & $.909^{* *}$ \\
\hline
\end{tabular}

$\mathrm{SHI}=$ Speech Handicap Index . ${ }^{*} p<.05,{ }^{* *} p<.01$.
Table 6. Validity analysis for the SHI and SHI-15

\begin{tabular}{lcc}
\hline SHI domain & Numbers of items & $\begin{array}{c}\text { Correlation between SHI and SHI-15 } \\
\text { (Pearson's } \text { ) }\end{array}$ \\
\hline Total & 15 & $.993^{* *}$ \\
Speech & 8 & $.982^{* *}$ \\
Psychosocial & 7 & $.984^{* *}$ \\
\hline
\end{tabular}

$\mathrm{SHI}=$ Speech Handicap Index. ${ }^{* *} p<.01$. 
Table 7. Item discrimination of SHI-15

\begin{tabular}{cc}
\hline Item & Item discrimination (Pearson's $)$ \\
\hline 1 & $.902^{* *}$ \\
2 & $.796^{* *}$ \\
3 & $.904^{* *}$ \\
4 & $.839^{* *}$ \\
5 & $.895^{* *}$ \\
6 & $.904^{* *}$ \\
7 & $.776^{* *}$ \\
8 & $.769^{* *}$ \\
9 & $.927^{* *}$ \\
10 & $.856^{* *}$ \\
11 & $.905^{* *}$ \\
12 & $.931^{* *}$ \\
13 & $.933^{* *}$ \\
14 & $.891^{* *}$ \\
15 & $.937^{* *}$ \\
\hline
\end{tabular}

$\mathrm{SHI}=$ Speech Handicap Index .

${ }^{* *} p<.01$.

Table 8. Sensitivity and specificity of SHI-15

\begin{tabular}{lcccc}
\hline SHI domain & Sensitivity $(\%)$ & Specificity $(\%)$ & AUC & $p$-value \\
\hline Total & 77.1 & 80 & .825 & $<.001$ \\
\hline
\end{tabular}

$\mathrm{SHI}=$ Speech Handicap Index; $\mathrm{AUC}=$ area under curve. ${ }^{*} p<.05$.

당도를 알아본 결과 총점에서 $\mathrm{AUC}$ 면적은 .825 , 민감도는 $77.1 \%$, 특 이도는 $80 \%$ 로서 높은 민감도 및 특이도를 나타냈다 $(p<.05)$ (Table 8 , Figure 1).

\section{논의 및 결론}

본 연구에서는 설암 환자들이 수술 후 발생하는 말 문제에 대한 환자 스스로의 인식을 평가하는 $\mathrm{SHI}$ 의 축소판인 SHI-15를 개발하 여, SHI-15이 삶의 질 측정에 효율적인 도구적 역할을 할 수 있도록 기대하였다. 연구결과에 준하여, 본 연구는 다음의 두 가지 의의를 지니고 있음을 확인하였다.

첫째, SHI-15는 설암 환자에 대해 말장애 인식 정도를 수치화함 으로써 이들의 삶의 질을 객관적으로 측정할 수 있었다는 점이다. 재활을 개시하기 전에 진행되는 평가에 있어서 필수적이 된 삶의 질(QOL) 관련 자기보고 평가는 대상자가 자신의 문제를 직면하는 데에는 말 평가 결과 자체도 중요하지만 본인이 겪고 있는 자기 인 식 역시 삶의 질에 중대한 영향을 미치기 때문이다. 삶의 질 측정은 환자의 관점에서 신체적, 정신적, 사회적인 요소를 반드시 포함해

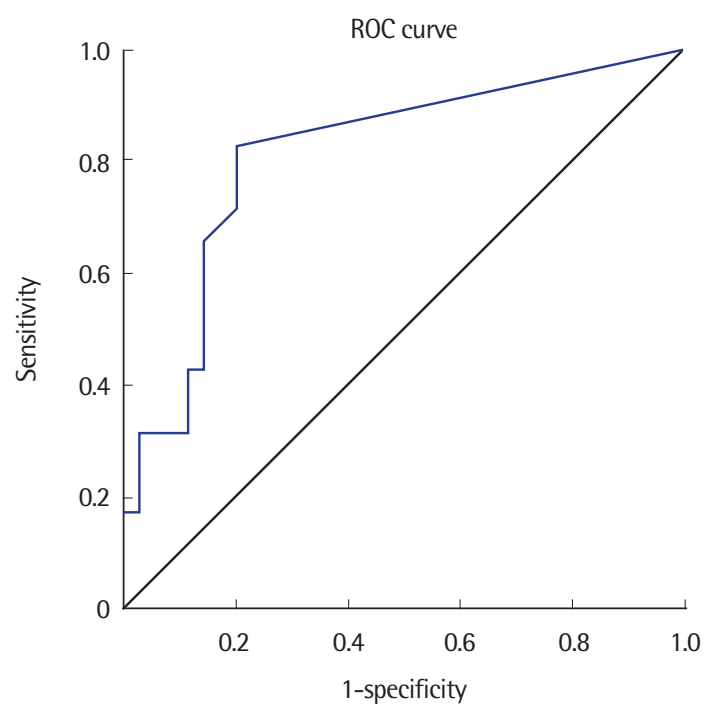

Figure 1. ROC curve analysis of the SHI-15.

$\mathrm{SHI}=$ Speech Handicap Index; ROC = receiver operating characteristic.

야한다(Cella \& Cherin, 1988).

한국판 SHI의 신뢰도와 타당도를 본 선행연구(Park et al., 2016) 와 본 연구와의 차이점은 선행연구의 대상자들의 경우, 구강, 구인 두암 환자들이었으나 본 연구는 56명의 설암 환자들만을 포함하였 다는 점이다. 설암은 다른 구강암 부위에 비해 말장애를 일으킬 확 률이 훨씬 높은데, 혀 등의 구강 구조가 말 산출에 직접적인 관련성 이 있기 때문이다. 두경부암 환자들 중 후두암의 경우에는 ‘말’보다 는 ‘음성’ 문제를 보이는 경우가 더 많으며, 실질적으로 전반적인 두 경부 환자들에 대한 삶의 질 연구는 '말' 문제에 대한 고찰 이전에 ‘음성’ 문제에 집중되어 왔다(Karlsen et al., 2017). 음성장애지수 (Voice Handicap Index)를 통해 확인할 수 있는 부분은 신체적 측 면에서 후두의 불편감과 발성의 문제에 대한 인식을 알아보는 것이 고, 기능적 측면에서 일상적 활동에서 음성장애의 정도를 알아보 는 것이며 정서적 항목으로 음성장애로 인한 감정의 반응을 알아 보는 것이다. 이 도구 또한 신체적, 정신적 사회적 요소를 포함하나 ‘음성' 문제에 집중되어 있다. 이에 비해, SHI는 말 기능과 심리사회 적 기능으로 구성되어 있으며 '말' 문제를 측정하는 데 특화되어 있 다는 것에 큰 의의가 있다.

본 연구의 두 번째 의의로는 본 연구에서 개발된 축소판 SHI-15 가 SHI (30개 문항)와 비교하여 큰 차이 없이 평가도구로서의 유용 성을 지니고 있다는 점이다. SHI-15는 말 기능 하위영역 문항 8개, 심리사회적 기능 하위영역 문항 7 개를 포함한 총 15 개 문항으로 구 성된, 삶의 질을 측정하는 도구로 적합함을 나타냈다. 말 기능 하위 영역 문항이 더 많은 비율을 차지하는 것은 SHI-15가 말 평가에 특 
화된 도구인 SHI의 개발 목적과 맥락을 같이 한다. 그뿐만 아니라 높은 신뢰도와타당도, 높은 민감도 및 특이도를 가진다. 민감도 및 특이도는 환자군을 정상군과 구별하여 진단할 수 있는 정도를 말 하는 것으로 이를 통해 환자군과 정상군을 구별할 수 있는 도구인 지를 판단한다. 즉, 본 SHI-15점수를 통해 환자군과 정상군을 구별 할 수 있는 평가도구로서 큰 의의를 지닌다.

$\mathrm{SHI}$ 의 항목들 중 22 번과 23 번은 말 기능, 심리사회적 기능의 두 항목에 해당하지 않으면서 총점에만 영향을 주었는데, SHI-15에서 는 이 두 문항이 제외되었다. 그 중 22 번 문항은 '재정'에 해당하는 문항으로, 이는 삶의 질을 평가하는 도구 중 UW-QOL에 관한 연 구결과와 유사하다. UW-QOL을 5년 동안 재평가한 연구에서, 본 도구의 12 가지의 하위 항목 중 검사자 간 일치율이 낮은 2 가지 항목 으로 '구강건조'와 '고용'이 해당하였다(Weymuller, Alsarraf, Yueh, Deleyiannis, \& Coltrera, 2001). 이 두 항목은 다른 10 가지의 항목 에 비해 반응의 변이성이 높았는데, 이와 비슷한 이유로 '재정'에 해 당하는 SHI의 22번 문항이 SHI-15에서도 제외되었다고 할 수 있을 것이다. 이러한 변이성이 높은 문항들을 제외하여 개발되었음에도 SHI와 높은 상관성을 보였기 때문에 SHI-15는 SHI를 대체할 수 있 는 도구임을 나타낸다. 게다가, SHI-15은 설암 환자들뿐만 아니라 다양한 말장애 대상자들에게 적용이 가능하도록 관련 전문가 2명 에게 자문을 받아 문항을 선정하였다. 또한 SHI와 SHI-15의 평가 실시 시간을 비교하였을 때, 소요시간이 절반으로 줄었다. 즉, 적은 문항 수로 시간적인 유용성을 갖는 SHI-15는 평가프로토콜의 검사 로서 포함될 것이다. $\mathrm{VHI}$ 역시 문항 수 측면에서 여러 버전으로 연 구된 도구로서, VHI-85, VHI-30 (Jacobson et al., 1997), VHI-10 (Rosen et al., 2004) 등으로 다양하다. VHI 또한 시간의 효율성을 높이기 위해 다양한 버전으로 연구되었는데 이는 SHI의 축소판이 개발이 필요하였음을 뒷받침해준다.

이처럼 본 연구의 여러 의의에도 불구하고 제한점이 있을 수 있 는데, 첫째로는 연구 대상자 수에 따라 다른 결과를 가져올 수 있다 는 점이다. 무엇보다도 본 연구에서 적용한 라쉬분석은 적합도의 통계치는 통계적인 검정방법을 사용하기 때문에 표본 크기에 영향 을 받기 때문이다(Kim et al., 2012). 또한 대상자를 종양의 크기와 발병 후 기간(POT)의 구분이 없이 모집했다는 점과 연구별 혹은 그룹별 성비가 동일하지 않다는 것이다. 그러나 성비의 경우 남, 여 그룹 간 점수에 유의미한 차이가 없었기 때문에 연구결과에 큰 영 향을 주지는 않으나 향후 연구에서 동일한 성비로 구성된 대상군 으로 연구한다면 좀 더 정확한 연구가 될 것이다.

그럼에도 불구하여, 본 연구에서 확인된 SHI-15의 유용성에 따 라 SHI-15가 향후 임상현장에서 말장애 환자들의 삶의 질 측정에
공헌할 수 있으며, 평가프로토콜의 항목으로 자리잡게 되기를 기대 해 본다. 현재 $\mathrm{SHI}$ 를 다양한 언어로 번안하여 신뢰도와 타당도를 보는 연구가 활발하게 진행되고 있다. 그러나 축소판 개발 연구는 현재까지 부재하기에, 이 점이 본 연구에서 강조될 의의일 것이다.

\section{REFERENCES}

Bond, T., \& Fox, C. M. (2007). Applying the Rasch model: fundamental measurement in the human sciences (2nd ed.). New York, NY: Routledge.

Boone, D. R., McFarlane, S. C., Von Berg, S. L., \& Zraick, R. I. (2013). The voice and voice therapy (9th ed.). Boston, MA: Pearson.

Cella, D. F., \& Cherin, E. A. (1988). Quality of life during and after cancer treatment. Comprehensive Therapy, 14, 69-75.

Ferlay, J., Soerjomataram, I., Dikshit, R., Eser, S., Mathers, C., Rebelo, M., ... \& Bray, F. (2015). Cancer incidence and mortality worldwide: sources, methods and major patterns in GLOBOCAN 2012. International Journal of Cancer, 136, e359-386.

Fingeret, M. C., Hutcheson, K. A., Jensen, K., Yuan, Y., Urbauer, D., \& Lewin, J. S. (2013). Associations among speech, eating, and body image concerns for surgical patients with head and neck cancer. Head \& Neck, 35, 354-360.

Funk, G. F., Karnell, L. H., Christensen, A. J., Moran, P. J., \& Ricks, J. (2003). Comprehensive head and neck oncology health status assessment. Head \& Neck, 25, 561-575.

Funk, G. F., Karnell, L. H., Robinson, R. A., Zhen, W. K., Trask, D. K., \& Hoffman, H. T. (2002). Presentation, treatment, and outcome of oral cavity cancer: a National Cancer Data Base report. Head \& Neck, 24, 165-180.

Jacobson, B. H., Johnson, A., Grywalski, C., Silbergleit, A., Jacobson, G., Benninger, M. S., \& Newman, C. W. (1997). The voice handicap index (VHI): development and validation. American Journal of Speech-Language Pathology, 6, 66-70.

Kang, E. K., Jeong, H. S., Moon, E. R., Lee, J. Y., \& Lee, K. J. (2016). Cognitive and language function in aphasic patients assessed with the Korean version of mini-mental status examination. Annals of Rehabilitation Medicine, 40, $152-161$.

Karlsen, T., Sandvik, L., Heimdal, J. H., Hjermstad, M. J., Aarstad, A. K. H., \& Aarstad, H. J. (2017). Health-related quality of life as studied by EORTC QLQ and Voice Handicap Index among various patients with laryngeal disease. Journal of Voice, 31, 251.e17-251.e26.

Karnell, L. H., Funk, G. F., \& Hoffman, H. T. (2000). Assessing head and neck cancer patient outcome domains. Head \& Neck, 22, 6-11. 
Kim, S. J., Shin, J. C., Kim, D. Y., \& Kim, H. (2012). Korean version of Stroke and Aphasia Quality of Life Scale-39(K-SAQOL-39): its validity and reliability. Journal of Rehabilitation Research, 16, 245-265.

Park, S. S., Choi, S. H., Hong, J. A., Hong, Y. H., Jeong, N. G., Lee, S. Y., ... \& Hah, J. H. (2016). Validity and reliability of the Korean version of the Speech Handicap Index in patients with oral cavity cancer. International Journal of Oral and Maxillofacial Surgery, 45, 433-439.

Rinkel, R. N., Leeuw, I. M., van Reij, E. J., Aaronson, N. K., \& Leemans, C. R. (2008). Speech Handicap Index in patients with oral and pharyngeal cancer: better understanding of patients' complaints. Head \& Neck, 30, 868874.

Rogers, S. N., Gwanne, S., Lowe, D., Humphris, G., Yueh, B., \& Weymuller, E. A. (2002). The addition of mood and anxiety domains to the University of Washington quality of life scale. Head \& Neck, 24, 521-529.

Rosen, C. A., Lee, A. S., Osborne, J., Zullo, T., \& Murry, T. (2004). Develop- ment and validation of the Voice Handicap Index-10. The Laryngoscope, $114,1549-1556$

Sadura, A., Pater, J., Osoba, D., Levine, M., Palmer, M., \& Bennett, K. (1992). Quality-of-life assessment: patient compliance with questionnaire completion. Journal of the National Cancer Institute, 84, 1023-1026.

Terrell, J. E., Nanavati, K. A., Esclamado, R. M., Bishop, J. K., Bradford, C. R., \& Wolf, G. T. (1997). Head and neck cancer-specific quality of life: instrument validation. Archives of Otolaryngology-Head \& Neck Surgery, 123, 1125-1132.

Weymuller, E. A., Alsarraf, R., Yueh, B., Deleyiannis, F. W. B., \& Coltrera, M. D. (2001). Analysis of the performance characteristics of the University of Washington Quality of Life instrument and its modification (UW-QOLR). Archives of Otolaryngology-Head \& Neck Surgery, 127, 489-493.

World Health Organization. (2001). International Classification of Functioning, Disability and Health (ICF). Geneva: Author. 
Appendix 1. Speech Handicap Index

Speech Handicap Index (Korean version)

이름:

나이:

성별: 남 / 여

* 다음 문장을 읽고 현재 말 상태에 맞는 곳에 동그라미 표시해주세요

$0=$ 전혀 없다 $1=$ 거의 없다 $2=$ 가끔 있다 $3=$ 자주 있다 $4=$ 항상 있다

1) 사람들은 내 말을 이해하기 어려워한다

2) 나는 말할 때 숨이 찬다.

3) 나의 말 정확도(명료도)는 하루에도 여러 번 달라진다.

4) 나는 말 때문에 무능력하게 느껴진다.

5) 사람들은 내 말을 이해하지 못하고 나에게 되물어본다.

6) 사람들이 나에게 다시 말해달라고 하면 짜증이 난다.

7) 나는 전화사용을 피한다.

8) 나는 말 때문에 다른 사람과 대화할 때 긴장한다.

9) 나는 발음이 부정확하다.

10) 사람들은 시끄러운 곳에서 내 말을 이해하기 어려워한다.

11) 대화 시 말 문제 때문에 사람들이 많은 상황을 피하는 경향이 있다.

12) 사람들은 내 말을 귀에 거슬려 하는 듯하다.

13) 마주보고 대화할 때, 사람들은 나에게 되물어본다.

$\begin{array}{lllll}0 & 1 & 2 & 3 & 4\end{array}$

14) 나는 말의 문제로 인해 친구, 이웃 혹은 친척들과 말을 덜하게 된다.

15) 나는 말할 때 중압감을 느낀다.

16) 다른 사람들은 나의 말에 문제가 있다고 느낀다.

17) 나는 말 문제로 인해 개인 및 사회생활에 제한을 받는다.

18) 말 정확도를 예측할 수 없다.

19) 나는 말 문제 때문에 소외감을 느낀다.

$\begin{array}{lllll}0 & 1 & 2 & 3 & 4\end{array}$

20) 나는 말을 정확하게 하기 위해 노력을 한다.

21) 저녁이 되면 말소리가 더 나빠진다.

22) 나는 말 문제로 인해 수입이 줄었다.

23) 나는 말소리를 정확히 내려고 노력한다.

24) 나는 말 문제 때문에 화가 난다.

25) 나는 말 때문에 외부활동을 덜 한다.

26) 내가 집에서 가족들을 부를 때, 가족들은 잘 알아듣지 못한다.

27) 나는 말 문제 때문에 장애가 있다고 느겨진다.

28) 나는 말 문제 때문에 대화를 계속(지속)하기 어렵다.

$\begin{array}{lllll}0 & 1 & 2 & 3 & 4\end{array}$

$\begin{array}{lllll}0 & 1 & 2 & 3 & 4\end{array}$

$\begin{array}{lllll}0 & 1 & 2 & 3 & 4\end{array}$

29) 나는 사람들이 다시 말해달라고 하면 당혹스럽다.

30) 나는 말 문제로 인해 수치심을 느낀다.

$\begin{array}{lllll}0 & 1 & 2 & 3 & 4\end{array}$

$\begin{array}{lllll}0 & 1 & 2 & 3 & 4\end{array}$

$\begin{array}{lllll}0 & 1 & 2 & 3 & 4\end{array}$

$\begin{array}{lllll}0 & 1 & 2 & 3 & 4\end{array}$

$\begin{array}{lllll}0 & 1 & 2 & 3 & 4\end{array}$

$\begin{array}{lllll}0 & 1 & 2 & 3 & 4\end{array}$

$\begin{array}{lllll}0 & 1 & 2 & 3 & 4\end{array}$

$\begin{array}{lllll}0 & 1 & 2 & 3 & 4\end{array}$

$\begin{array}{lllll}0 & 1 & 2 & 3 & 4\end{array}$

$\begin{array}{lllll}0 & 1 & 2 & 3 & 4\end{array}$

$\begin{array}{lllll}0 & 1 & 2 & 3 & 4\end{array}$

$\begin{array}{lllll}0 & 1 & 2 & 3 & 4\end{array}$

$\begin{array}{lllll}0 & 1 & 2 & 3 & 4\end{array}$

$\begin{array}{lllll}0 & 1 & 2 & 3 & 4\end{array}$

$\begin{array}{lllll}0 & 1 & 2 & 3 & 4\end{array}$

$\begin{array}{lllll}0 & 1 & 2 & 3 & 4\end{array}$

$\begin{array}{lllll}0 & 1 & 2 & 3 & 4\end{array}$

$\begin{array}{lllll}0 & 1 & 2 & 3 & 4\end{array}$

$\begin{array}{lllll}0 & 1 & 2 & 3 & 4\end{array}$

$\begin{array}{lllll}0 & 1 & 2 & 3 & 4\end{array}$

$\begin{array}{lllll}0 & 1 & 2 & 3 & 4\end{array}$

$\begin{array}{lllll}0 & 1 & 2 & 3 & 4\end{array}$

$\begin{array}{lllll}0 & 1 & 2 & 3 & 4\end{array}$

$\begin{array}{lllll}0 & 1 & 2 & 3 & 4\end{array}$

$\begin{array}{lllll}0 & 1 & 2 & 3 & 4\end{array}$


Appendix 2. Revised edition of Speech Handicap Index

Speech Handicap Index (Korean version)

이름:

나이:

성별: 남 / 여

* 다음 문장을 읽고 현재 말 상태에 맞는 곳에 동그라미 표시해주세요.

$0=$ 전혀 없다 $\quad 1=$ 거의 없다 $2=$ 가끔 있다 $3=$ 자주 있다 $4=$ 항상 있다

1) 사람들은 내 말을 이해하기 어려워한다.

2) 나는 말할 때 숨이 찬다.

3) 나의 말 정확도(명료도)는 하루에도 여러 번 달라진다.

4) 나는 말 때문에 무능력하게 느껴진다.

*5) 사람들은 왜 내 말이 이해하기 어려운지를 내게 물어본다.

6) 사람들이 나에게 다시 말해달라고 하면 짜증이 난다.

7) 나는 전화사용을 피한다.

8) 나는 말 때문에 다른 사람과 대화할 때 긴장한다.

9) 나는 발음이 부정확하다.

10) 사람들은 시끄러운 곳에서 내 말을 이해하기 어려워한다.

11) 대화 시 말 문제 때문에 사람들이 많은 상황을 피하는 경향이 있다.

12) 사람들은 내 말을 귀에 거슬려 하는 듯하다.

13) 마주보고 대화할 때, 사람들은 나에게 되물어본다.

14) 나는 말의 문제로 인해 친구, 이웃 혹은 친척들과 말을 덜하게 된다.

*15) 나는 말할 때 힘을 줘서 말해야 할 것 같다.

*16) 다른 사람들은 나의 말 문제를 이해하지 못하는 것 같다.

17) 나는 말 문제로 인해 개인 및 사회생활에 제한을 받는다.

18) 말 정확도를 예측할 수 없다.

*19) 나는 말 문제 때문에 대화에서 소외감을 느낀다.

20) 나는 말을 정확하게 하기 위해 노력을 한다.

21) 저녁이 되면 말소리가 더 나빠진다.

22) 나는 말 문제로 인해 수입이 줄었다.

23) 나는 말소리를 정확히 내려고 노력한다.

24) 나는 말 문제 때문에 화가 난다.

25) 나는 말 때문에 외부활동을 덜 한다.

26) 내가 집에서 가족들을 부를 때, 가족들은 잘 알아듣지 못한다.

27) 나는 말 문제 때문에 장애가 있다고 느껴진다.

28) 나는 말 문제 때문에 대화를 계속(지속)하기 어렵다.

29) 나는 사람들이 다시 말해달라고 하면 당혹스럽다

30) 나는 말 문제로 인해 수치심을 느낀다.

\begin{tabular}{lllll}
0 & 1 & 2 & 3 & 4 \\
0 & 1 & 2 & 3 & 4 \\
0 & 1 & 2 & 3 & 4 \\
0 & 1 & 2 & 3 & 4 \\
0 & 1 & 2 & 3 & 4 \\
\hline 0 & 1 & 2 & 3 & 4 \\
0 & 1 & 2 & 3 & 4 \\
0 & 1 & 2 & 3 & 4 \\
0 & 1 & 2 & 3 & 4 \\
0 & 1 & 2 & 3 & 4 \\
\hline 0 & 1 & 2 & 3 & 4 \\
0 & 1 & 2 & 3 & 4 \\
\hline 0 & 1 & 2 & 3 & 4 \\
\hline 0 & 1 & 2 & 3 & 4 \\
0 & 1 & 2 & 3 & 4 \\
\hline 0 & 1 & 2 & 3 & 4 \\
0 & 1 & 2 & 3 & 4 \\
\hline 0 & 1 & 2 & 3 & 4 \\
\hline 0 & 1 & 2 & 3 & 4 \\
0 & 1 & 2 & 3 & 4 \\
\hline 0 & 1 & 2 & 3 & 4 \\
0 & 1 & 2 & 3 & 4 \\
0 & 1 & 2 & 3 & 4 \\
\hline 0 & 1 & 2 & 3 & 4 \\
\hline 0 & 1 & 2 & 3 & 4 \\
\hline 0 & 1 & 2 & 3 & 4 \\
\hline 0 & 1 & 2 & 3 & 4 \\
\hline 0 & 1 & 2 & 3 & 4 \\
\hline 0 & 3 & 4 \\
\hline 0
\end{tabular}

*Revised items: 5, 15, 16, 19 


\section{국문초록}

\section{한국판 말장애지수(Speech Handicap Index)의 축소판 개발 및 설암 환자의 적용}

위선아 ${ }^{1} \cdot$ 최은창 $\cdot$ 조성래 ${ }^{3} \cdot$ 최성희 ${ }^{4} \cdot$ 김향희 $^{1,3}$

${ }^{1}$ 연세대학교 대학원 언어병리학협동과정, ${ }^{2}$ 연세대학교 의과대학 이비인후과학교실, ${ }^{3}$ 연세대학교 의과대학 재활의학교실, ${ }^{4}$ 대구가톨릭대학교 언어청각치료학과

배경 및 목적: 말장애지수(Speech Handicap Index, SHI)는 말 평가에 필수적으로 실시되는 자기보고 평가로서, 구강이나 구인두암 환 자의 말 기능과 심리사회적 기능을 평가하는 데 특화되어 개발된 도구이다. SHI가 말 문제를 평가하기에 적합하게 개발되었음에도 불 구하고 30 개라는 전체 문항 수는 시간적인 제약을 받는다. 따라서 이 연구에서는 설암 환자를 대상으로 축소판을 개발하고 신뢰도와 타당도를 검증하고자 하였다. 방법: 이 연구는 총 두 단계로 진행되었다. 연구단계 I에서는 설암 환자 56명을 대상으로 SHI를 실시한 후, WINSTEPS의 라쉬분석(Rasch analysis)을 통해 총 15 문항으로 축소되었고 이 축소판을 설암환자뿐만 아니라 다양한 말장애군에 게 적용하기 위해 관련 분야 전문가 2 명의 자문을 받아 최종본을 확정하였다. 최종적으로 말 기능 8 문항, 심리사회적 기능 7 문항, 총 15 개 문항으로 구성된 SHI-15가 완성되었다. 연구단계 II에서 설암 환자 35명과 정상군 35명에게 SHI (30개 전체문항)와 SHI- 15 (15개 문 항)를 각각 실시하였고, 신뢰도와 타당도를 검증하였다. 결과: SHI-15는 높은 문항내적일관성과 검사-재검사 신뢰도를 보이는 신뢰도 높은 도구임을 검증되었다. 또한 SHI와 SHI-15점수를 비교하였을 때, 높은 상관성을 보임으로써, SHI- 15 는 SHI를 대체하여 사용할 수 있는 도구임이 검증되었다. 뿐만 아니라, 높은 문항변별도와 환자군과 정상군 두 집단 간의 유의미한 차이로 높은 타당도를 검증하였으 며 높은 민감도 및 특이도를 보였다. 논의 및 결론: 이 연구는 SHI-15가 시간적 효율성을 가지는 동시에 환자 자신의 말 문제에 대한 인 식, 심리적 기능과 말 문제의 효율성을 평가하는 도구가 될 것임을 보여준다. 앞으로 SHI-15는 임상에서 말 문제와 관련된 환자들의 삶 의 질을 평가하는 통상적인 도구로 활용될 것이다.

핵심어: 말장애지수(Speech Handicap Index), 설암, 말장애, 삶의 질, 라쉬분석

\section{참고문헌}

김수정, 신지철, 김덕용, 김향희(2012). 뇌졸중 후 실어증 환자의 삶의 질 척도 (SAQOL-39): 한국어판의 타당도 및 신뢰도. 재활복지, 16, 245-265. 